\title{
A Strategy Study on Risk Communication of Pandemic Influenza: A Mental Model Study of College Students in Beijing
}

This article was published in the following Dove Press journal: Risk Management and Healthcare Policy

\author{
Honglin Yang (D) \\ Xiaoping Pang ${ }^{2}$ \\ Bo Zheng ${ }^{3}$ \\ Linxian Wang ${ }^{4}$ \\ Yadong Wang' \\ Shuai Du' \\ Xinyi Lu'
}

'School of Health Education and Administration, Capital Medical University, Beijing 100069, People's Republic of China; ${ }^{2}$ Logistics Department, Da Zhou Centre Hospital, Da Zhou, Si Chuan, 635000, People's Republic of China; ${ }^{3}$ Department of Scientific Research, Beijing Children's Hospital, Capital Medical University, National Center for Children's Health, Beijing 100045, People's Republic of China; ${ }^{4}$ Business School, Cardiff University, Cardiff CFIO 3XQ, UK
Correspondence: Honglin Yang Email 407457292@qq.com
Purpose: To understand the characteristics of risk perception of influenza pandemic in college students with prominent frequency and the differences between these risk perceptions and professionals. Then, offering a proposal for the government to improve the efficiency of risk communication and health education.

Methods: According to the mental model theory, researchers first draw a framework of key risk factors, and then they ask these students about the understanding of the framework with questionnaire and then making concept statistics and content analysis on the respondents' answers.

Results: Researchers find some students' misunderstanding of pandemic including excessive optimism to the consequences of a pandemic, a lack of detailed understanding of mitigation measures, and negative attitudes towards health education and vaccination. Most students showed incomplete and incorrect views about concepts related to the development and exposure factors, impact and mitigation measures. Once threatened, it may lead to the failure of decisionmaking. The majority of students we interviewed had positive attitudes towards personal emergency preparedness for a pandemic influenza and specialized health education in the future. Conclusion: Researchers suggest that the government should make a specific pandemic guidance plan by referring to the risk cognitive characteristics of college students shown in the research results, and update the methods of health education to college students.

Keywords: risk communication, pandemic influenza, mental model, health emergency, health education

\section{Introduction}

Influenza, which is a highly variable infectious disease that can quickly evolve into a pandemic, can pose a significant threat to people's health. ${ }^{1}$ The corresponding emergency response measures require the active cooperation of the public to work effectively. Because of its wide range of impact and potential mortality, effective risk communication will help the public understand information related to influenza. $^{2}$

Compared to risk communication in other fields, when public health events occur, the government often turns to experts to ask them what the public should know. So, it is a challenge that how to effectively transform scientific knowledge into useful structures and non-professional backgrounds. ${ }^{3}$ Our researchers use influence diagrams from mental model interview to analyze the critical risk factors of flu, which can improve student's ability of decision-making to maintain their physical health. ${ }^{4-8}$ Morgan et als monograph on mental model theory argues that everyone relies on 
their mental models to understand information. It grows into a unique and intrinsic pattern as individuals grow, similar to a workflow chart. Splitting the outside world into multiple components to help us understand may not be perfect; however, it affects our way of thinking and behavior choice. $3,9,10$ A person's mental model is influenced by various factors, including personal experience, acquired learning, and living environment, and these factors are changeable and also important in affecting our health-related behaviors., $311-15$ Therefore, targeted education can help an individual correct misunderstanding in their mental models and then improve their risk management.

In China, there is no application of mental model theory in the field of health education and no special pandemic preparedness guideline for the general public. However, in Western countries, particularly the United States, many scholars have conducted substantial research in this area. Lazrus et al have studied the public mountain flood communication framework in Boulder County, Colorado State. ${ }^{16}$ Casman et al ${ }^{17}$ used the influence map to establish a dynamic risk model for waterborne cryptosporidiosis, which defines "key awareness variables" in risk communication and assigns scores for evaluation. Our researchers hope to use the mental model theory to analyze the most critical risk factors of influenza pandemic from a broader perspective and find out college students` risk perception of these factors. The understanding and cognitive characteristics help improve the communication work of the government, which is the aim of this article.

\section{Materials and Methods}

\section{Communication Framework and Key}

\section{Concepts}

This study refers to the impact map formed by Morss et al in the flood risk communication of Boulder County ${ }^{18}$ and draws the risk factor framework of the influenza pandemic. The entire frame is an analysis of disaster events from a macro perspective, including "causes," "development," "response," "event impact" and "risk information dissemination." Then, through literature research and expert consultation, the researchers summarized the concept of the communication framework and initially formed its content suitable for the influenza epidemic. The content of the whole frame consists of the causes of influenza epidemics, the impact of pandemics, emergency preparedness and strategies of different groups, risk information, and emergency response decisions, as shown in Figure 1.

The researchers subsequently searched for the corresponding supporting documents according to the content of the framework and conducted expert seminars. Combined with the materials of the literature and expert opinions, the authors initially wrote identical concept items under each part of the frame. Finally, we used the Delphi method to invite 18 experts from the related fields to judge the structure, importance and scientific nature of these items. ${ }^{19}$

\section{Sample and Interview Content}

The purpose of mental model interviews is to determine which concepts or beliefs are "out there" with sufficient frequency such that in smaller samples, these concepts or beliefs become reasonable. There is no standard method for determining sample size in relevant theories and research practice. $^{3}$ According to Professor Morgan's monograph and related research examples, the sample size for a mental model interview should be $20 \sim 30$, at which point new information has reached saturation. ${ }^{3}$ Based on these research facts, combined with the research design of Lazrus and Morss, ${ }^{16,18}$ we recruited the first 30 respondents from 5 randomly selected non-medical college by telephone and posters. To avoid confounding bias, these

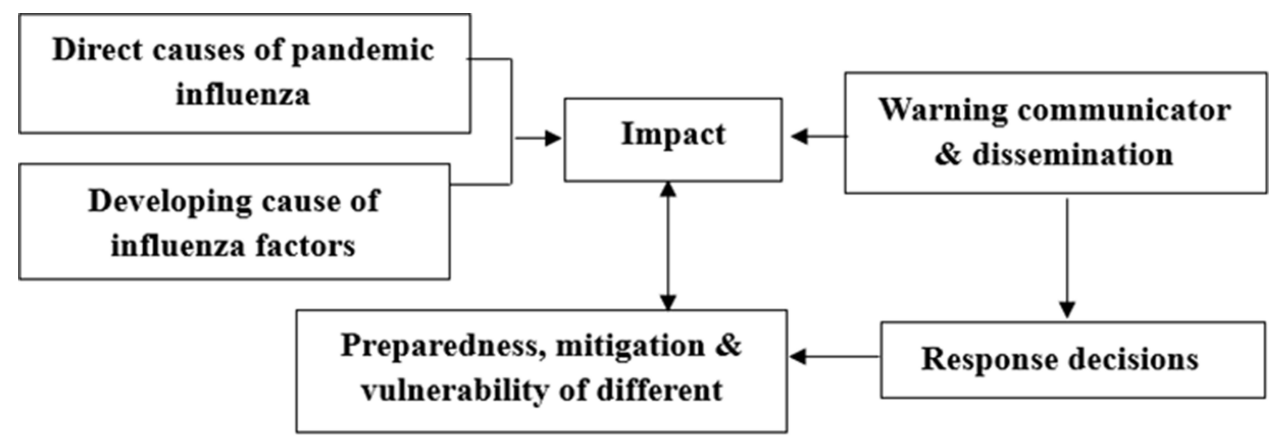

Figure I The basic framework of standardized communication for influenza. Including key risk factors, the six boxes in the figure represent the critical risk factors that comprise a pandemic, and the arrows represent the relationships among the factors. 
students are also from non-medical majors (including Russian, finance, urban planning and marketing) and have not studied medical related professional courses. After all the investigations have been completed, we discussed the results and deleted two poor interview results, and then drew a line chart of information saturation according to the number of concepts mentioned by the respondents in Figure 2. We found that after the 22nd interviewee, information saturation began to show a downward trend, and subsequent respondents did not propose new concepts. We believe that the information provided by these 28 respondents can meet the sample size required for the analysis of this study, because the purpose of mental model study is not to use statistical methods to analyze the distribution of some risk cognition in the population, but to find out which concepts or beliefs, are "out there" with some reasonable frequency, ${ }^{3}$ so as to help government departments identify what should be focused on when developing guidance programs and health education materials for this population.

The interview began with an open question, such as "please tell us about the pandemic." Our investigators guided the respondents to elaborate on their main concepts, then details of the outbreak, as well as the mitigation measures that should be employed. If the interviewer had experienced emergencies, then they were encouraged to talk about the decision or idea at that time. The interview results were subsequently transcribed, encoded and classified using the coding software ATLAS.ti. We also conducted a quantitative analysis of the results of the compilation, then created a statistical chart, observed the degree of attention of the respondents, and compared these results with the risk perception of experts to determine the interviewee's understanding of the related concepts and other features.

The questions used in this interview refer to a questionnaire in the study of Skarlatidou et al. ${ }^{20}$ The interview covers the content in Figure 1. Two researchers simultaneously coded the results of the interviews. The classification consistency index (Holsti reliability) of the coder was subsequently calculated, ${ }^{21}$ which fluctuated between 0.624 and 0.965 , and the average reliability statistic was 0.749. According to the study of Boyatzis and Burrus, the coding reliability of trained different coders ranges from 0.74 to $0.80 ;{ }^{22}$ therefore, the reliability of the coder was within the normal range and displayed adequate consistency.

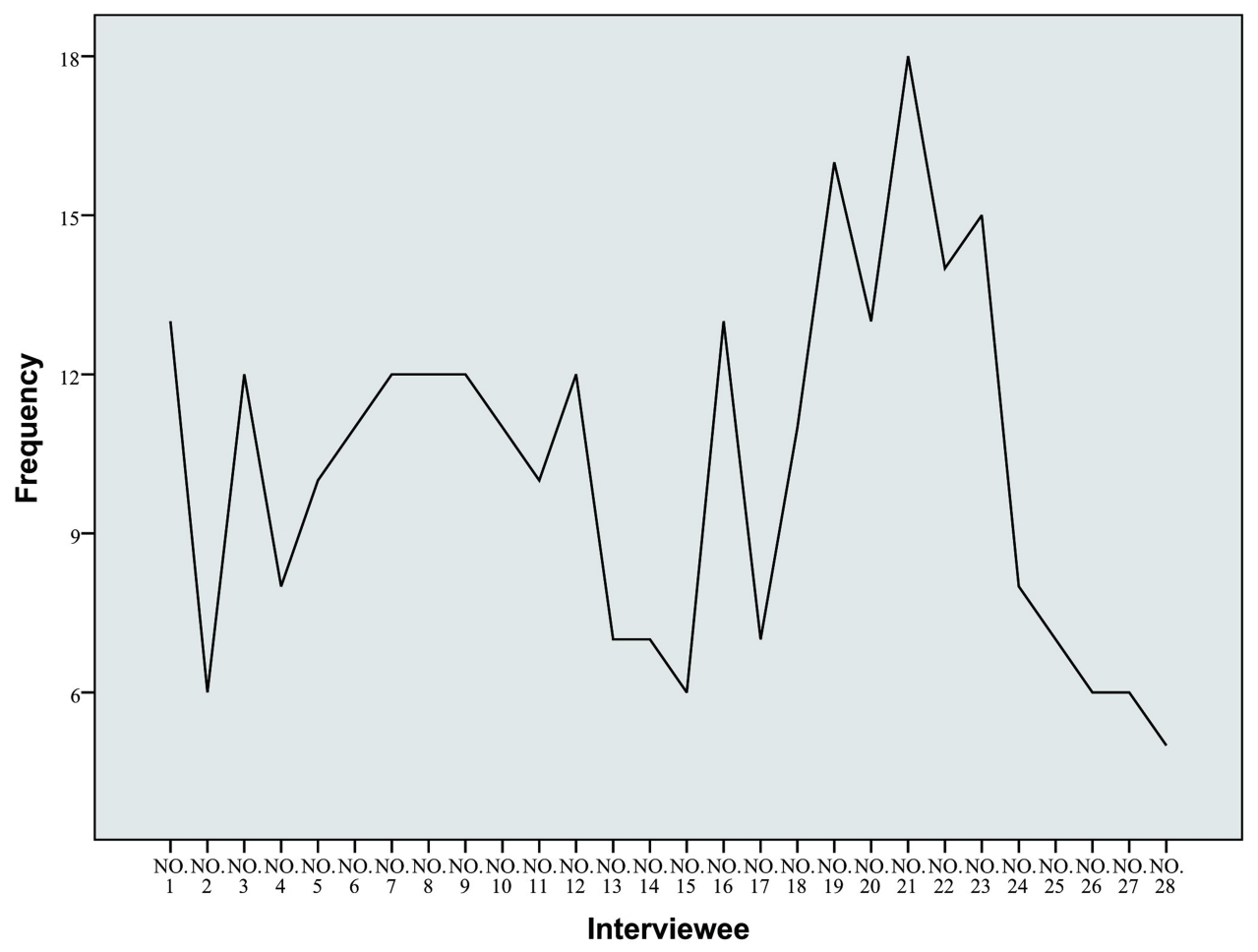

Figure 2 Information saturation trend provided by 28 respondents. For each of the respondents' answers to the number of concepts noted, the researchers first mapped the scatter plots. Then, to better show the increase and decrease in the information provided by the respondents, polylines were used to connect the points. The content of the concept is derived from the framework of Figure 3 and is described by the responses of all 28 respondents. 
Table I Coordination Coefficient of Expert Consultation

\begin{tabular}{|l|l|l|l|}
\hline \multirow{2}{*}{ Category } & \multicolumn{3}{|l|}{ Statistical Indicators } \\
\cline { 2 - 4 } & W & $\chi^{2}$ & P \\
\hline Ist round of consultation & 0.291 & 555.371 & $<0.001$ \\
2nd round of consultation & 0.324 & 298.623 & $<0.001$ \\
\hline
\end{tabular}

Note: Table I shows the statistical coefficient calculation results of the two Delphi studies, and the $\mathrm{P}$ values of the two coefficients all meet the requirements.

\section{Results}

\section{Expert Consultation Results}

Here is the result of two rounds of Delphi expert consultation. The value of the authority coefficient is $0.885(>0.70)$, which indicates that the study has a good expert score. ${ }^{19,23,24}$
As shown in Table 1, in the first round of expert consultation, the coordination coefficient of each item was 0.291 ( $P<0.001)$, and in the second round of expert consultation, the coordination coefficient was $0.324(\mathrm{P}<0.001)$, which was better than the first round and indicates that the opinions of the experts are consistent from the perspective of significance test. ${ }^{25}$ Finally, we created a communication framework for an influenza pandemic, as shown in Figure 3. It serves as the basis for our investigation of the problem content of college students and can also be regarded as a kind of "standardized communication content". The respondent may have a higher probability of taking the correct protective measures if he has a good understanding of the entire framework.

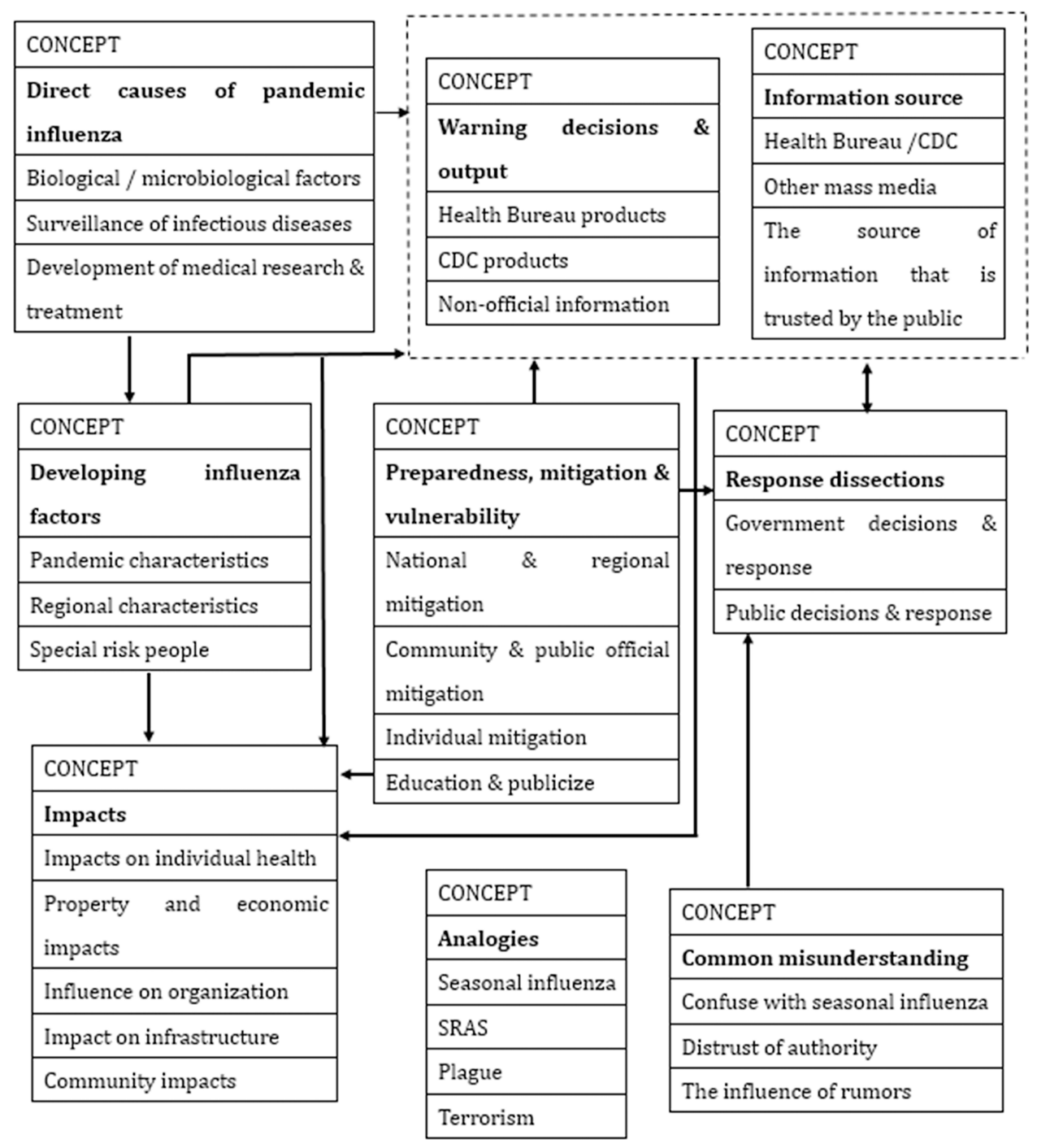

Figure 3 Communication framework of pandemic influenza. The frame is composed of six main conceptual dimensions; the central concept is the bold label, and the 2ndlevel concept in the box is the part. More complicated concepts in the framework are omitted; refer to the coding manual in the appendix. The whole frame contains 79 concepts, and the arrowhead represents the influence relationship of each part. The analogy part is listed separately to describe the events associated with the respondents. 


\section{Results of the Mental Model Interview Overall Situation}

The researchers counted the percentage of respondents that mentioned a concept item. Also, this study used a stacked bar chart to show the number of concepts mentioned by the 28 respondents (Figure 3). As shown in the graph, we distinguish the concept of different attributes in terms of dimensions (risk factors). The richness of the color can visually distinguish the depth of the mental model of each interviewee [the number of concepts mentioned by an interviewee], and we can determine which dimensions of the expert's risk perception the public is highly aware of and in which areas the public lacks awareness. Furthermore, the length of the bar graph reflects the number of concepts mentioned in the dimension: a taller bar graph reflects more relevant concept items indicated by the respondents and a deeper degree of understanding of the related content. For example, respondents 12, 16 and 21 knew more about the emergency response decisions during the pandemic, whereas interviewee \#24 was less aware in this regard.

Figure 4 shows the differences in thinking about the risk of and coping with the influenza pandemic among different groups. Even with a higher education level, each college student interviewee displayed a significant difference in the depth and detail of their mental model. Some of the respondents' mental models appear particularly "scarce" (such as respondents \#2 and 25). Nearly all respondents discussed less information than the risk perception of experts. Only one interviewee (Interviewee \#9) cited concepts that reflected almost all the parts of the communication framework in Figure 2. The other students did not suggest many more new concepts in the interview. Their conceptual descriptions reflect the concern for specific content and common cognitive deficiencies and misunderstandings. The following sections discuss these best features of the interview answers.

\section{The Formation and Development of the Pandemic}

The interactions between multiple factors may affect the formation and development of pandemic influenza. Several factors mentioned by our respondents are shown in Table 2; $39 \%$ of the respondents believed that influenza virus variation was an essential cause of the pandemic. They used statements such as "new virus," "virus mutation," and "an unknown virus." Additionally, 32\% of the respondents referred to disease surveillance, which included "poor supervision of the source of infection" and "unchecked work",

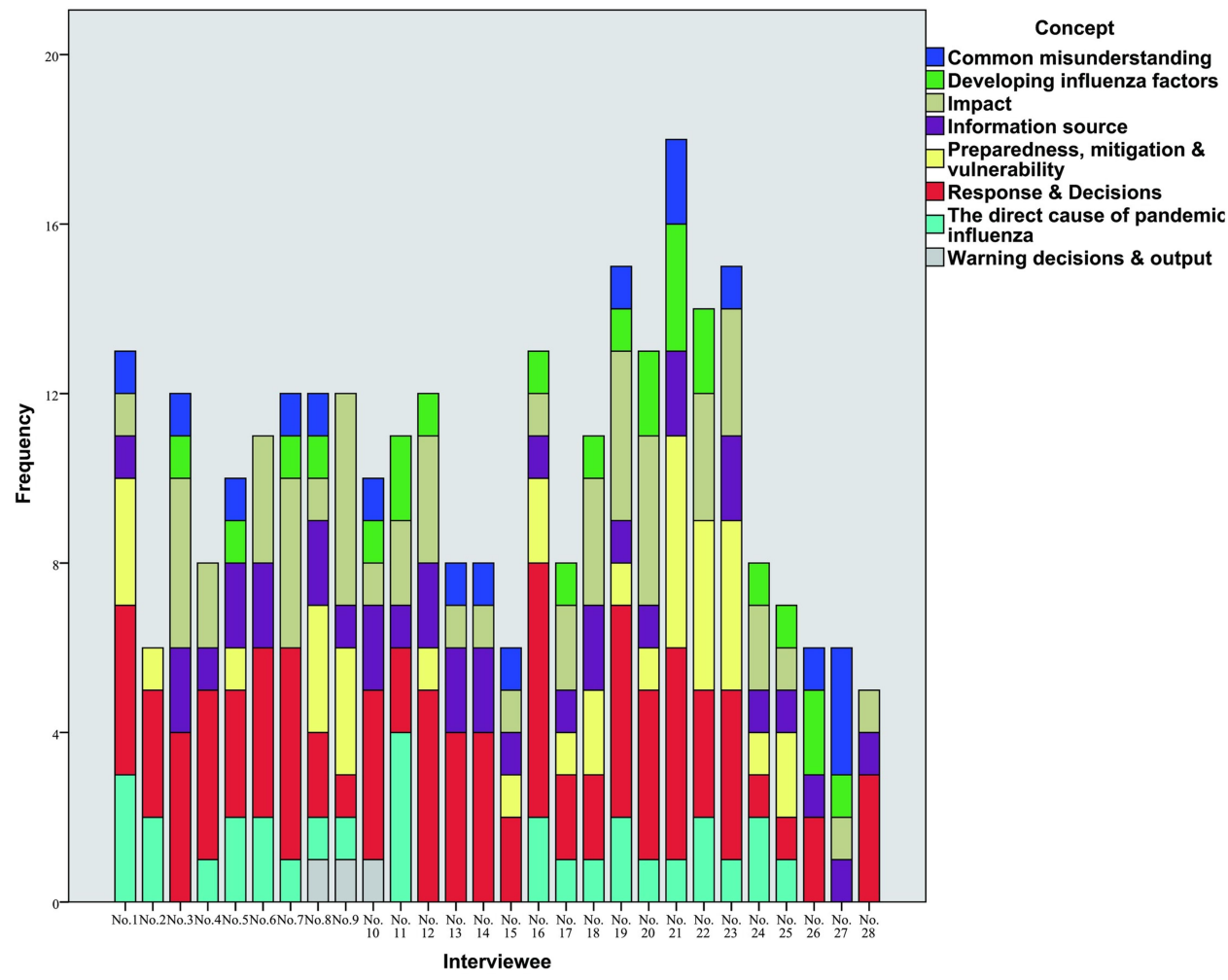

Figure 4 Variability in the number of concepts mentioned by the different respondents. The straight bars in the graph represent the number of concepts in Figure 3 that were described by each interviewee. Different colors represent the corresponding conceptual categories. The more colors a respondent has in the bar, the higher the range of understanding of the Figure 2 he or she may have. 
Table 2 The discussion of Related Items

\begin{tabular}{|l|l|l|}
\hline Concept & Frequency & Ratio \\
\hline Virus mutation & 11 & $39 \%$ \\
Virus infectious force & 5 & $17 \%$ \\
Drug resistance of the virus & 4 & $14 \%$ \\
Vaccination and related research & 2 & $7 \%$ \\
Disease surveillance network & 9 & $32 \%$ \\
Lack of immunity & 4 & $14 \%$ \\
International dissemination & 9 & $32 \%$ \\
Floating population density & 13 & $46 \%$ \\
Health emergency capacity & 4 & $14 \%$ \\
\hline
\end{tabular}

Note: Table shows the conceptual statistics of the causes of pandemic outbreaks mentioned by respondents.

and they were more inclined to use terms to express their views (for example, "gene mutation", "isolation treatment", "infrared surveillance", and "take the body temperature"). Forty-six percent of the respondents cited characteristics related to the international spread of the pandemic. Interviewee \#6 indicated "foreign virus carriers from foreign places into Beijing." However, some respondents believed that climate factors could lead to flu cases because they confused pandemic influenza with seasonal flu, such as interviewee \#7, who answered "when the seasons change, people may catch a cold easily. If they do not pay attention, a pandemic will happen if they don't do that." Many respondents $(46 \%)$ also cited the impact of population density, including densely populated places and more floating cities with higher risk areas for influenza. Other factors were less frequently cited by less than $17 \%$ of interviewee, including virus resistance, viral power, avian influenza immunity, and a human lack of immunity to new viruses.

Compared to the experts, the mental models of many of the students interviewed contained only part of the communication framework. Although some key factors were cited by most of the respondents, other essential factors were rarely cited or were misunderstood by the respondents. For example, interviewee \#16 believed that the flu was a "foodborne disease" and "caused by drugs." For individuals infected with influenza, no respondents discussed the impact of vulnerable groups on the development of the pandemic, and there was no further detailed description of the virus variation. A full understanding of these information can help people to evaluate the risk level in the environment, including which situations may have a higher risk of infectious diseases. Another neglected concept is the lethality of the virus. No respondents mentioned this concept or discuss the content related to us. In fact, the lethal rate is also an important indicator of a new infectious virus. ${ }^{26}$ From the perspective of scientific disease control, the lethal rate affects whether the virus has the characteristics of limited regional transmission (for example, Ebola virus, its lethal rate is $50-90 \%$, making the virus only intermittently epidemic in individual countries and regions, with certain limitations in time and space.) ${ }^{27}$ From the perspective of promoting public participation in disease response, highrisk events can promote individual polar to make protective decisions. ${ }^{28}$ Knowing the virulence of the virus can avoid the negative attitude to personal disease prevention caused by fluke psychology.

\section{The Impact and Consequences of a Pandemic}

As shown in Table 3, approximately $29 \%$ of the respondents discussed the fatality of the flu, while only $14 \%$ of the respondents described the severe symptoms that could occur after the infection, such as interviewee \#5: “ $\ldots$ if there goes a pandemic, it would be more than a common cold. Runny nose and sneezing or, maybe, pneumonia?" None of the respondents cited complications related to influenza infection. Even if a real pandemic is only composed of common symptoms of fever and fatigue, complications such as pneumonia, myocarditis, and bronchitis are the real causes of death in some vulnerable patients. ${ }^{29,30}$ Therefore, although most of the respondents understood that the flu could have serious health threats, they did not understand how people die as a result of the flu. These misunderstandings may be related to some respondents' personal and onesided understanding of the pandemic and the lack of targeted health education. For example, interviewee \#10 stated "That is, people usually do not pay attention to clothes, then they catch a cold. It is quite a normal situation every year."

Table 3 The Discussion of Related Items

\begin{tabular}{|l|l|l|}
\hline Concepts & Frequency & Ratio \\
\hline More severe symptoms similar to the & 4 & $14 \%$ \\
common flu & & \\
Death of patients & 8 & $29 \%$ \\
Unable to work & 6 & $21 \%$ \\
Social and medical burden & 9 & $32 \%$ \\
Damage to critical posts in the organization & 3 & $11 \%$ \\
Absenteeism for employees & 1 & $4 \%$ \\
Impact on public infrastructure & 13 & $46 \%$ \\
Mass transmission & 4 & $14 \%$ \\
Panic within the community & 6 & $21 \%$ \\
\hline
\end{tabular}

Note: Table shows some of the concepts related to the likely impact of a pandemic mentioned by respondents. 
Most respondents also discussed the social and economic impacts of the pandemic, and $46 \%$ of the respondents referred to negative effects on schools, shops, public transport, and other infrastructure during the pandemic, such as interviewee \#14: "schools may shut down ... The shops outside may be closed because of this disease, and the economy may be seriously affected because everyone will hide at home." Most of the types of infrastructure, of which transportation was the most frequently cited, were generally quoted as examples of people during the SARS or bird flu period, such as interviewee \#11 who stated, "everyone is not going out at the time of the outbreak ... wearing a mask if you have to go outside." Thirty-two percent of the respondents were worried about overburdened hospital patients during the pandemic. Some of the respondents (28\%) also imagined disastrous consequences, including the impact of the pandemic on the community. According to interviewee \#16,

For a long time ... Our life may be threatened, many people steal food and drugs and will be locked inside their house ... not just the direct impact, it will bring other serious problems.

Although the respondents mentioned the relevant concepts in the communication framework, they fail to understand the severe damage that pandemic influenza could cause to individual health; moreover, they are not fully aware of panic actions during the outbreak. The most common panic behavior is to escape from the epidemic area. To avoid disaster is people's instinctive behavior, especially in the outbreak of infectious diseases. ${ }^{31}$ In fact, during the outbreak of the novel coronavirus (COVID-19) in China, people in some areas fled the outbreak area. And it happened to be the Chinese New Year's holiday. Lots of college students returned home to celebrate festival, which strongly increased the risk of virus transmission. Although these situations have not caused irreparable serious consequences, they have also brought great interference to the case investigation and disease monitoring in all provinces of the country.

Surprisingly, there are $30 \%$ of the respondents believed that a negative impact of a flu pandemic would be minimal or more positive, and nearly all of them stated that it "feels like the pandemic is far away from me." According to interviewee \#23, it "is a kind of epidemic disease, but speaking of cold and flu, what is generally not a major disease, easier to treat the feeling, plus the pandemic, it is only a larger scope of infection, right?" The content reflects that some students do not pay substantial attention to public health and their health. More people choose to passively wait and accept the strategies and measures employed by the school or the state government; they lack the initiative to understand the relevant information and take preventive actions.

\section{The Countermeasures of the Pandemic}

The coping strategies in Table 4 are essential to pandemic emergency work and a necessary part of the communication framework in Figure 2. Twenty-nine percent of the respondents cited the importance of personal hygiene habits, such as wearing masks and isolating patients; however, there are not many people who provided detail regarding these aspects. A few respondents described these strategies on the government, organization, and individual levels. Most of them referred to "masks" and "be far away from the cough" in the relevant description and noted details of whether to use a special mask or separate the patient from the family. For example, interviewee \#6 stated: "if it is a more serious situation, we will wear a mask, and then the hospital will be more nervous about the flu ... " Another $18 \%$ of the respondents believed that there was no need to isolate the suspected patients, such as interviewee \#19: "You cannot go to the hospital first because most of the cases are not true flu, to the hospital may be isolated, so look first." For the government's decision-making, 57\% of the respondents cited health education and counseling.

Most of them were willing to accept the necessary emergency response; over $1 / 4$ of the respondents referred to influenza surveillance, public disinfection, and hospital treatment. These answers demonstrate these students still make mistakes and lack of understanding of the most effective protection decisions, although they have better educational backgrounds and a high degree of potential

Table 4 The Discussion of Related Items

\begin{tabular}{|l|l|l|}
\hline Concept & Frequency & Ratio \\
\hline Clinical treatment and cadaver handling & 10 & $36 \%$ \\
Virus surveillance & 9 & $32 \%$ \\
Disinfection in public places & 7 & $25 \%$ \\
Vaccine preparation & 7 & $25 \%$ \\
Anti-influenza drugs & 5 & $18 \%$ \\
Professional and technical training & 2 & $7 \%$ \\
Education and consultation & 16 & $57 \%$ \\
Social isolation & 20 & $71 \%$ \\
Wear a special mask & 14 & $50 \%$ \\
Good personal hygiene & 8 & $29 \%$ \\
\hline
\end{tabular}

Note: Table shows respondents' discussion of the pandemic response. 
coordination. Moreover, although vaccination is the most effective way to prevent the flu, only two of the respondents said they were willing to receive the flu vaccine, and the other respondents said they would not vaccinate themselves if it were not compulsory. "There is no need for voluntary vaccination" (Respondents 3 and 17), "some vaccines may have side effects ... it will hurt me" (Interviewee 26). Notably, interviewee \#9, who originated from Hong Kong, was able to describe all the individual and government contingency strategies and discussed his own experience of avian influenza in Hong Kong in addition to elaborating on the entire process of emergency work. This fully embodies the maturity and perfection of the Hong Kong government in the risk communication of emergencies and the higher risk awareness. Thus, the related communication and publicity strategies are worth referencing.

\section{The Acquisition of Risk Information and Public Suggestion}

The risk of pandemic influenza can be reduced by timely warning, access to correct information, and attitudes towards communication and interest in the face of threats. As shown in Table 5, 50\% of the respondents had a specific information identification ability; $43 \%$ of the respondents chose to obtain their information on pandemic risk from the official channels. All respondents were willing to take several methods to search for risk information, including using the Internet. However, although knowing first-hand influenza warning and decision support information originates from the $\mathrm{CDC}$, very few of the respondents $(10 \%)$ were able to clarify what types of communicators can provide help and detailed descriptions on this topic,

Table 5 The Discussion of Related Items

\begin{tabular}{|l|l|l|}
\hline Concept & Frequency & Ratio \\
\hline Complete negation of self-media & 5 & $18 \%$ \\
Dialectical view of self-media & 14 & $50 \%$ \\
Willing to participate in publicity & 8 & $29 \%$ \\
Refusing to participate in publicity & 20 & $71 \%$ \\
Access to information from the authority & 12 & $43 \%$ \\
Access to information from other mass media & 14 & $50 \%$ \\
Obtaining information from other trusted & 13 & $46 \%$ \\
sources & & \\
Differences between pandemic and seasonal & 4 & $14 \%$ \\
influenza & & \\
The influence of rumors & 7 & $25 \%$ \\
\hline
\end{tabular}

Note: Table shows the concept of risk information mentioned by respondents and their Suggestions on current government risk communication. including the specific types of early warning information that is available, where the information is, and how it is transmitted. Individuals have only mastered the general concept, such as interviewee \#11: “... go to the official website or WeChat (to) find how to prevent." For health education and publicity, most of the respondents indicated that they would not take the initiative to participate in similar activities. The reasons were "traditional lectures are boring," "the publicity manual was not attractive". Moreover, as interviewee \#25 indicated, "I think all of them are theoretical knowledge which can be seen on the Internet. If they can tell us something that you need to deal with when an event comes, it would be better."

Regarding suggestions for future risk communication. Most of the respondents were satisfied with the current government's work and had a positive attitude towards the emergency plan of the official guide form; they were more focused on "the details of the emergency work" (cited by $25 \%$ of the respondents) and "hope to get official plan" (cited by $21 \%$ of the respondents). For example, interviewee 20 indicated that " ... the way must be change, not as before, because the flu is not like a common cold, people will not pay much attention to it. Communication, whether it is a family or school, it is best to have some specific suggestions, such as how to wash hands and disinfection, everyone can refer to themselves to do it."

\section{Discussion}

In general, there was a clear difference in the breadth and depth of the overall understanding of the pandemic-related information and communication framework among each student interviewed. As expected, in the context of the communication framework, most of the students' mental models were not as rich as those of the experts. They were more concerned with the critical information necessary to make individual decisions in the interpretation of risk information, for example, Interviewee \#10 says: "Now, I want to know what type of impact will it cause, and what type of protection measures can protect me?" Most respondents only referred to the critical concepts in the communication framework, without a detailed description or in an inaccurate or unclear manner; therefore, these gaps may reduce the ability of people to manage their behavior and their compliance with expert opinions. Compared to the communication framework in Figure 2, the respondents used personal experience and analogies to produce more related concepts to establish the information base they needed to make decisions. 


\section{The Causes of Misunderstandings}

The infection of flu often brings many complications, in the heart and lung systems, to those who have low immunity, such as infants and young children, and these are also the significant causes of virus' potential lethality. ${ }^{30,32}$ The interview results show that some students do not pay sufficient attention to the impact of pandemic influenza and remain optimistic, particularly the lethality of virus, serious complications, and identification of vulnerable populations. Our respondents trust in the country's sound epidemic prevention system. However, because we still have a lot of unknown information to explore about the virus, the outbreak of a new virus often brings challenges to the health system of a region. For example, virus identification, targeted program formulation, and information release all need time. For the existence of these time lags between case generation and interventions, if we want to carry out successful disease control actions, it is more important for the public to actively carry out personal protection rather than passively wait for the intervention of government departments. Moreover, the desalination of the history of the epidemic, and the lack of targeted health education may also be reasons for the over-optimism of the pandemic. Consequently, those who have inaccurate risk perception will estimate themselves as "the strongest young people" or "a person who having enough understanding about the flu." Once a new virus outbreaks, these people may also bring misleading information to other individuals in their social circle, which will affect others' emergency decisions. In particular, for those who have experienced influenza pandemic without being negatively affected, luck may cause them to have a more positive response to future pandemics. ${ }^{33,34}$

Furthermore, although the H1N1, H5N1, and other influenza outbreaks have been derived from new viruses following mutation, the repetition of the old virus and the prevention of the flu season risk becoming a pandemic. ${ }^{31}$ Being able to distinguish the key differences between the pandemic and common flu can effectively improve the level of personal risk cognition. Among the respondents, we found that some students remained confusion: they believed that a pandemic is the mass spread of seasonal influenza or a pandemic is an almost impossible "super calamity". Moreover, a pandemic is often unpredictable and generally involves international outbreak. Therefore, it is important for the public to understand that the pandemic is not far away from us. We need to pay attention to our own prevention during the flu season, and at the same time, we need to be alert to unusual cold symptoms, especially when we go abroad. Otherwise, patients may mistakenly think that they are suffering from common influenza, choose to place or take medicine, thus delaying the diagnosis and treatment time, infecting others and causing serious consequences.

Finally, concerning vaccination, our respondents have negative views regarding this issue. Only 2 of the 28 respondents cited the importance of the vaccine and had a history of active vaccination, and the reasons mainly focused on the conventional "I feel good and don't need vaccination" and "doubts about the safety of vaccines." Therefore, our risk communication at present seems inadequate in promoting the necessity of vaccination. The public is not aware of the importance of the vaccine for influenza prevention or the misperceptions caused by its one-sided understanding of the pandemic, as discussed in "The Countermeasures of the Pandemic". In an investigation of the willingness of the elderly to be vaccinated, Shaoliang Geng ${ }^{35}$ found that the primary sources of influenza and related knowledge in elderly adults were family, relatives, friends, and television, and the most trusted means of knowledge were doctors. There are cracks in clinical and public health knowledge, and patients lack knowledge about the importance of vaccination. The correction of this misunderstanding is vital for college students and because it can promote the dissemination of inoculation knowledge of young students in the family, thus improving the injection of the recommended groups (old people and young children).

\section{The Defect of Individual Mental Model}

As discussed in The Acquisition of Risk Information and Public Suggestion, in the absence of relevant knowledge and information, the respondents applied personal experiences and analogies to compose the foundation of their mental model and help themselves understand the risk of the pandemic. Understanding differences in causality between risk factors can also lead to substantial differences in risk perception and coping between individuals. ${ }^{33}$ Many students only know a few general concepts and have not formed a complete emergency preparedness mode of thinking in a communication framework, knowing what one can do during the pandemic but not much about what to do and what is truly meaningful. For example, although nearly all respondents cited wearing masks and bringing in patients in time for medical 
treatment, the most basic measures can be limited in the presence of a real pandemic, which is only a result of a personal experience analogy (compared to a cold or related disease). What ' $s$ more, for those in the outbreak area, especially those with suspected symptoms, it is the right and effective decision to stay at home and seek the help of local medical institutions to protect personal health than to conceal facts and escaping from outbreak area in panic. But none of our respondents know that.

Also, most respondents have only basic concepts (the government and the health department) regarding the types of communicators who provide the relevant risk information. These overly broad understandings may limit their ability to rapidly identify critical information or influence their knowledge of specific report under the threat of severe flu, mainly when their typical sources of information or communication channels are not available, or the necessary information is not provided. If the government is unable to offer exact messages or be out of protection from the spread of information. Public trust in official authority may be reduced.

\section{The Traditional Publicity Requires Improvement}

Students always prefer health education with new styles and systematic content. The appeal of traditional lectures and guideline books full of academic words is far less attractive, and it is hoped that the government will "reduce the over the generality of the description" and "release relevant data to increase persuasion" in future communication work. Foltz's research confirms that it is necessary to use various mechanisms in the risk communication of emergencies. Individuals with nonprofessional backgrounds tend to think in more specific terms, their vocabulary is less expansive, and subtle expressions cannot be well understood. Bright colors and charts easily attract them. Complex text information transmission will make people feel tired and irritable. ${ }^{2}$ If possible, two student respondents also suggested organizing practical exercises, which they think is more helpful to deepen the impression and understand self-protection measures used to cope with the pandemic. Information consistency is the decisive factor in understanding and perceiving personal risk. In terms of communication effectiveness, multiple sources of consistent messages are typically more effective than messages from a single source or with different contents. ${ }^{36}$ The earlier the warning people receive and the higher the threat of information is, the higher the possibility that people take active preventive measures. Therefore, the government department should incorporate the outbreak situational information and the proposed measures into influenza warnings, while maintaining the consistency of multiple communication messages.

\section{Conclusion and Proposal}

First, the results of this research reflect some misunderstanding in the respondents with a more prominent frequency: 1) influenza virus mutation and seasonal influenza have the potential to evolve into a pandemic, and the prevention of common influenza cannot be ignored. 2) the impact of an influenza pandemic is often unprecedented, and influenza virus infection can be lethal; in addition to severe cold symptoms, it also results in severe complications in patients. 3) influenza vaccination plays an active role in pandemic prevention and should be actively vaccinated, particularly children with low immunity and elderly adults, a vulnerable group. 4) for suspected patients in the family, the first choice is a social isolate, and it is very dangerous for family members to remain in close contact with their protection work. It is imperative for individuals to have common knowledge regarding influenza, the correct personal response and the degree of risk in our area for making the right decisions. Therefore, we suggest that the government should put the above content as the focus of communication when communicating the risks related to the pandemic, or formulating the corresponding health education materials, so as to improve the compliance of the audience.

On the other hand, the content of government risk communication should not be limited to medical advice. The public health department should develop a response plan for individuals and organizations. In terms of organization, a pandemic does not directly damage related facilities in contrast to many other catastrophic events. However, the regular work of employees within the organization will be affected. The absence of ill employees in central positions will have a severe impact on the regular operation of the organization. Therefore, we need to develop a "continuous work plan" for these particular circumstances. The government should release relevant risk information on an influenza pandemic in the form of a preparation plan, or, use the network for distance health education or guiding emergency response work through local radio or television stations. 
Finally, we should update the channels and methods of risk communication and health education. The government should strengthen the application of new media to adapt to young people's information acquisition preferences. In the form of communication, it can be gradually changed from traditional lectures to novel approaches, such as public welfare videos, songs, and scene construction experiences. Moreover, scene effects can play an essential role in enhancing the personal experience because analogies are encountered in the event of a risk event to facilitate their correct risk assessment and response behavior.

\section{Acknowledgments}

The authors would like to acknowledge Linxian Wang for helping compiling interview questionnaires, making suggestions on interview skills and finding supporting documents. We also express the sincere gratitude to students involved in the interviews of this research. This research did not involve any experiments or investigation which need ethical approval, and did not receive any specific funding too.

\section{Disclosure}

The authors report no conflicts of interest for this work.

\section{References}

1. Glik DC. Risk communication for public health emergencies. Annu Rev Public Health. 2007;28:33-54. doi:10.1146/annurev.publhealth. 28.021406.144123

2. Slovic P, ed. The Perception of Risk. London: Earthscan; 2001:10-13.

3. Morgan MG, Fishhoff B, Bostrom A, et al. Risk Communicaiton: A Mental Models Approach. Cambridge University Press; 2002:145-147.

4. Tversky A, Kaheman D. Rational choice and the framing of decisions. J Bus. 1986;59:5251-5278. doi:10.1086/296365

5. Brookes T. A Warning Shot: Influenza and the 2004 Flu Vaccine Shortage. Washington, DC: American Public Health Association; 2006:20-24.

6. Peters RG, Covello VT, McCallum DB. The determinants of trust and credibility in environmental risk communication: an empirical study. Risk Anal. 1997;17(1):43-54. doi:10.1111/j.1539-6924.1997. tb00842.x

7. Xinhua News. Available from http://news.xinhuanet.com/2016-07/ 24/c_1119268989.htm. Accessed August 06, 2020.

8. McCombs M, Reynolds A. News influence on our pictures of the world. In: Media Effects: Advances in Theory and Research. 2nd. Jennings B, Zillman D, editors. Mahwah, NJ: Earlbaum;2001. 1-18, 69-93.

9. Berland GK, Elliott MN, Morales LS, et al. Health information on the Internet: accessibility, quality, and readability in english and spanish? JAMA. 2001;285(20):2612-2621. doi:10.1001/jama.285.20.2612

10. Covello VT. 2003 Best Practices in Public Health Risk and Crisis Communication? J Health Commun. 1990;8:5-8. doi:10.1080/713 851971
11. Fischoff B. Risk perception and communication unplugged: twenty years of progress. Risk Anal. 1995;15(2):137-145. doi:10.1111/ j.1539-6924.1995.tb00308.x

12. Beck U. Risk Society. Ho Po Wen Translation. Nanjing Yilin press; 2004:67,95,37,39.

13. Fischoff B, Lichentenstein S, Slovic P. Acceptable Risk. New York: Cambridge; 1981:20-23.

14. Craik KW. The Nature of Explanation. Cambridge UK: Cambridge University Press; 1943:25-26.

15. Solvic P, Fishhoff B, Lichtenstein S. Rating the Risk. In: Readings in Risk. Glickman Ts, Gough M, editors. Washington, DC: Resour. Fut; 1990:20-25, 61-75.

16. Lazrus H, Morss RE, Demuth JL, Lazo JK, Bostrom A. "Know what to do if you encounter a flash flood": mental models analysis for improving flash flood risk communication and public decision making. Risk Anal. 2016;36(2):395-416. doi:10.1111/risa.12480

17. Casman EA, Fischhoff B, Palmgren C, et al. An integrated risk model of a drinking-water - borne cryptosporidiosis outbreak. Risk Anal. 2000;20(4):495-512. doi:10.1111/0272-4332.204047

18. Morss RE, Demuth JD, Bostrom A, Lazo JK, Lazrus H. Flash flood risks and warning decisions: a mental models' study of forecasters, public officials, and media broadcasters in Boulder, Colorado. Risk Anal. 2015;5:70-71.

19. Jun X, Wang B, Chen P, et al. Application of Delphi method in screening self-rated health evaluation index system. Chin Acad J Abstr. 1999;5:34-38.

20. Skarlatidou A, Cheng T, Haklay M. What do lay people want to know about the disposal of nuclear waste? A mental model approach to the design and development of an online risk communication. Risk Anal. 2012;32(9):1501-1508. doi:10.1111/j.1539-6924.2011.01773.x

21. Kvale S. Validity in the qualitative research interview. Methods. 1987;1(2):37-42.

22. Boyatzis. $R E$ The Competent Manager: A Model for Effective Performance. New York: Wiley; 1982:52.

23. Xinqiang J, Liu Z. Delphi method and its application in medical research and decision making. Chin J Drug Depend. 2006; 15:422-426.

24. Wang T. Research on the Structure of Public Risk Communication Ability of Influenza Pandemic in Health Sector. Medical University of Anhui; 2009:1-49.

25. Cheng C, Liu Y, Kendall WL. Coordination coefficient W test and its SPSS implementation. Taishan Med Univ Rep. 2010;31(7):487-489.

26. Zheng X, Kangsheng L. Influenza century: review and enlightenment of influenza pandemic in the 20th century. Med Soc (Berkeley). 2010;11(23):4-6.

27. Cao Y, Wei S, Gongxian X. Discrete logistic dynamic model and its parameter identification for the ebola epidemic. J Bohai Univ. 2019;3:257-262.

28. Guang Z. Modern Epidemiology methods and Applications [M]. Beijing: Beijing Medical University Peking Union Medical College Joint Publishing House; 1996:250-270.

29. Zhou Y. Research on Monitoring and Evaluation Index System of National Essential Medicine System in Primary Health Care Institutions. Hubei: Hua Zhong University of science and technology; 2011:47-50.

30. Zhang C, Zhang W, Liao Z, et al. Analysis of the clinical characteristics of influenza A (H1N1). Chin J Nosocomial Infect. 2009;23:245-248.

31. Visschers VHM, Meertens RM, Passchier WF, deVries NK. How does the general public evaluate risk information? The impact of associations with other risks. Risk Anal. 2007;27(3):715-717. doi:10.1111/j.1539-6924.2007.00915.x

32. Erhart LM, Rangel MC, Lu P-J, et al. Prevalence and characteristics of children at increased risk for complications from influenza, United States, 2000. J Pediatrics. 2004;144(2):191-195. doi:10.1016/j.jpeds. 2003.11.007 
33. Ruiqian X, Jian L. Analysis of the information demand characteristics of public health emergencies of infectious diseases. Chin Health Educ. 2010;26(1):43-45.

34. Foltz AT, Sullivan JM. Limited Literacy revisited implications for patient education. Cancer Pract. 1999;7(3):145-150. doi:10.1046/ j.1523-5394.1999.07304.x
35. Shaoliang G, Yahui C, He C, et al. Investigation on knowledge and willingness of influenza vaccination among the elderly over 60 years old in Xuchang city. Mod Prev Med. 2017;2(44):299.

36. Ruin I, Lutoff C, Boudevillain B, et al. Social and hydrological responses to extreme precipitations: an interdisciplinary strategy for post-flood investigation. Weather Clim Soc. 2014;6(1):135-153. doi:10.1175/WCAS-D-13-00009.1

\section{Publish your work in this journal}

Risk Management and Healthcare Policy is an international, peerreviewed, open access journal focusing on all aspects of public health, policy, and preventative measures to promote good health and improve morbidity and mortality in the population. The journal welcomes submitted papers covering original research, basic science, clinical \& epidemiological studies, reviews and evaluations, guidelines, expert opinion and commentary, case reports and extended reports. The manuscript management system is completely online and includes a very quick and fair peer-review system, which is all easy to use. Visit http://www.dovepress.com/testimonials.php to read real quotes from published authors. 